\title{
Reliability and Durability Enhancement of Large-area Mullite-cordierite Composite Substrates for Semiconductor Probe Card
}

Da-Eun Hyun

Korea Testing Laboratory

Jwa-Bin Jeon

Kwangwoon University

Yeon-Ji Choi

Korea Testing Laboratory

Yeon-Sook Lee

Korea Testing Laboratory

Yong-Nam Kim

Korea Testing Laboratory

Minkyung Kim

Kwangwoon University

Seunghoon Ko

Kwangwoon University

Sang-Mo Koo

Kwangwoon University

Weon Ho Shin

Kwangwoon University

Chulhwan Park

Kwangwoon University

Dong-Won Lee

Kwangwoon University

Jong-Min Oh ( $\sigma$ jmOH@kw.ac.kr)

Kwangwoon University

\section{Research Article}

Keywords: Mullite, Cordierite, Composites, Environmental tests, Semiconductor probe cards

Posted Date: September 20th, 2021

DOl: https://doi.org/10.21203/rs.3.rs-882673/v1 
License: (c) (i) This work is licensed under a Creative Commons Attribution 4.0 International License. Read Full License 


\section{Abstract}

Spherical mullite (M)-cordierite (C) composite granules were prepared by spray drying the fine starting powders obtained from attrition milling to produce sintered mullite-cordierite composite pellets with a dense structure. The effects of attrition milling on the morphology, size and size distribution of the formed composite granules were investigated. The results showed that the milled starting powders formed the spherical granules with homogeneous size distribution. The composition ratio ( $M: C=100: 0$, $M: C=90: 10, M: C=70: 30, M: C=50: 50, M: C=30: 70, M: C=0: 100)$ and sintering temperature (1300$1450^{\circ} \mathrm{C}$ ) were optimized to fabricate the sintered mullite-cordierite composite pellets with low thermal expansion coefficients (TECs) and excellent mechanical properties. Samples of $70 \mathrm{wt} \%$ mullite-30 wt\% cordierite sintered at $1350^{\circ} \mathrm{C}$ exhibited excellent bulk density, porosity, TEC, and flexural strength. Based on these results, a large-area mullite-cordierite composite substrate was fabricated for application in semiconductor probe card. The changes in sheet resistance and flexural strength were measured to study the influence of the environmental tests, including high temperature storage test, damp heat test, and thermal shock test, on the large-area substrate. A low rate of change in sheet resistance and flexural strength was observed. After the environmental tests, the sheet resistance and flexural strength were confirmed to be within $10 \%$ of their values prior to the tests. These results show that the fabricated mullite-cordierite composite exhibits high reliability and durability and is a suitable for semiconductor probe cards.

\section{Introduction}

The probe card is a component that directly tests the operation of the IC chip integrated on the wafer. In recent years, the probe card has become important because not only size of the pads has decreased, but also spacing between the pads has become narrow with the miniaturization of electronic devices $[1,2]$. The ceramic substrate of a probe card has several required characteristics. Firstly, the probe card must have a low thermal expansion coefficients (TECs) similar to that of silicon for the wafer-level burn in test. The probe card cannot be used in to wafer-level burn-in test due to the unacceptable dimension errors due to the mismatch in the thermal expansion of the probe card and the silicon wafer [3]. Secondly, it is crucial to control the sintering shrinkage of the ceramic substrate of the probe card with many probe pins. The positions of the processed holes can deviate from the designed positions due to the shrinkage of the ceramic substrate during the sintering process. Therefore, it is important to consider ceramics with low TEC as candidate materials for semiconductor probe card and investigate the various factors affecting the sintering of ceramics.

Cordierite $\left(2 \mathrm{MgO} \cdot 2 \mathrm{Al}_{2} \mathrm{O}_{3} \cdot 5 \mathrm{SiO}_{2}\right)$ is considered a promising material for the probe card substrate owing to its attractive properties such as high thermal shock resistance, high resistivity, high refractoriness, chemical stability, and low TEC. Consequently, cordierite has been widely used in various applications, such as electrical insulator, refractories, filters, membranes, substrates for integrated circuit boards, and microwaves [4-7]. However, it is difficult to obtain cordierite ceramics with a dense structure as 
cordierites have a narrow sintering temperature and are difficult to sinter using the solid-state process [810].

Many studies have investigated different methods to improve the densification of cordierite ceramics by adding sintering aids. Banjuraizah et al. [11] found that the addition of $\mathrm{MgO}$ to cordierite glass improves the densification, but excessive addition of MgO increased the TEC. Chen $[12,13]$ also increased the density of cordierite-based glass ceramics by adding the sintering aids like $\mathrm{CaO}$ and $\mathrm{ZnO}$. The excess use of these sintering aids, however, caused an increase in the TEC and dielectric loss. Therefore, it is critical to select suitable materials to fabricate a dense ceramic substrate with a low TEC for use in probe cards.

Mullite $\left(3 \mathrm{Al}_{2} \mathrm{O}_{3} \cdot 2 \mathrm{SiO}_{2}\right)$ is not only well-known as a material that improves the mechanical properties of cordierite $[6,14,15]$, but is also used in electronic substrates, microelectronic packaging, and as a component in reinforced composites owing to its good electrical resistance, thermal shock resistance, excellent thermal and chemical stability at high temperatures, and good dielectric and mechanical properties [15-18]. Albhilil et al. [9] reported that the relatively low mechanical strength of cordierite can be improved by polymorphism transformation, although the TEC slightly increases by the addition of mullite. Subramanian et al. [19] proposed that chip detachment and device failure can be prevented by matching the TEC of the probe card substrate to that of Si. They also reported that a mullite-cordierite composite with $35: 65$ vol\% has a TEC that matches with Si.

In this study, we investigated the composition ratio of the composite ceramics and the factors that influence the sintering to fabricate a large-area mullite-cordierite composite substrate with excellent physical and mechanical properties. To investigate the effect of the particle size distribution on the sintered body, the microstructures of the composite granules before and after attrition milling were observed. The change in the sheet resistance and the flexural strength of the large-area mullite-cordierite composite substrate during various environmental tests were measured to evaluate its reliability and durability.

\section{Experimental Procedures}

\subsection{Materials and processing}

Commercially available powders of mullite (DAIHAN REFRACTORIES MATERIAL, Korea) and cordierite (Eastking Industrial Limited, China) were used as starting powders and labeled $\mathrm{M}$ and $\mathrm{C}$, respectively. Their median diameters $\left(D_{50}\right)$ of the mullite and cordierite powders were $3.96 \mu \mathrm{m}$ and $4.23 \mu \mathrm{m}$, respectively. The starting powders were then subjected to attrition milling for $24 \mathrm{~h}$ to investigate the effect of the particle size and size distribution on the formation of the granules. After that, the slurry was prepared to produce granules using starting powders with different weight percentages $(M: C=100: 0, M: C$ $=90: 10, M: C=70: 30, M: C=50: 50, M: C=30: 70, M: C=0: 100)$. To this slurry, polyvinyl alcohol (PVA) used as binder, dispersant, and releasing agent were added. $\mathrm{TiO}_{2}, \mathrm{Y}_{2} \mathrm{O}_{3}, \mathrm{Cr}_{2} \mathrm{O}_{3}$, and $\mathrm{MnO}$ powders were then added to the slurry as the sintering aid, and a small amount of $\mathrm{MgO}$ powder was also used as the 
sintering aid. Then, the slurry was ball-milled with $\mathrm{ZrO}_{2}$ balls for $3 \mathrm{~h}$ to form a uniform dispersion and spray dried. At the end of spray drying process, the dried granules were sieved and then uniaxially pressed into cylindrical pellets ( $36 \mathrm{~mm}$ in diameter and $6 \mathrm{~mm}$ in thickness) at $80 \mathrm{MPa}$ and sintered at a temperature ranging between $1300^{\circ} \mathrm{C}$ and $1450^{\circ} \mathrm{C}$ for $4 \mathrm{~h}$. The physical and mechanical properties of the resultant mullite-cordierite composites were analyzed to determine the optimum mixing ratio and the sintering temperature. The processing workflow for mullite-cordierite composites is shown in Fig. 1.

\subsection{Fabrication of large-area ceramic composite substrate}

To manufacture a large-area ceramic composite substrate for the semiconductor probe card, the granules of the mullite-cordierite composite with the optimal composition ratio were uniaxially pressed at $80 \mathrm{MPa}$ into ceramic substrates with a diameter of $320 \mathrm{~mm}$ and sintered at $1350^{\circ} \mathrm{C}$ for $4 \mathrm{~h}$. Subsequently, the substrates were subjected to surface grinding to reduce the shrinkage and warpage of the ceramic substrate during the sintering process. Considering the frequency and amplitude of the ultrasonic generator, the size of the processing pin and the processing pressure, ultrasonic drilling was performed and 30000 micro-holes were processed through it.

\subsection{Characterization procedure}

The average particle size of the starting powders was measured by a particle size analyzer (PSA, Bluewave, MICROTRAC, Japan). The microstructure of the mullite-cordierite composites was observed by field-emission scanning electron microscopy (FE-SEM, MIRA3 XMU, TESCAN, Czech Republic). The bulk density and the porosity were determined by the static weighing method according to ASTM C20 [20]. The TECs of the mullite-cordierite composites were measured with a thermomechanical analyzer (TMA, Q400, TA Instrument, USA) in a temperature range of $25-500^{\circ} \mathrm{C}$ using a $5^{\circ} \mathrm{C} / \mathrm{min}$ heating rate.

To evaluate the durability and the reliability of ceramic substrates made of mullite-cordierite composites, the specimens were prepared with dimensions of $80 \mathrm{~mm} \times 80 \mathrm{~mm}$ by processing the fabricated ceramic substrates. The environmental tests such as high temperature storage test, damp heat test, and thermal shock test were conducted to determine the changes in the properties of the specimens under the environmental conditions that cause failure. The high temperature storage (HTS) test was measured in an oven at $200^{\circ} \mathrm{C}$ for $100 \mathrm{~h}$. Damp heat (DH) test was conducted at $85^{\circ} \mathrm{C}$ and $85 \%$ relative humidity for $100 \mathrm{~h}$ in a chamber (WKE 64/70, WEISS, USA). The thermal shock (TS) test was carried out for 100 cycles using a thermal shock chamber (TSA-41L, ESPEC, Japan). One cycle consists of heating the substrate up to $85^{\circ} \mathrm{C}$ with a hold time of $30 \mathrm{~min}$, followed by cooling down to $-40^{\circ} \mathrm{C}$ with a hold time of $30 \mathrm{~min}$.

After the environmental tests, the sheet resistivity and flexural strength of the ceramic substrate were measured. The sheet resistivity was measured using a high resistance meter (Hiresta-UX MCP-HT 800, MITSUBISHI CHEMICAL ANALYTECH, Japan) at $1000 \mathrm{~V}$. Flexural strength was assessed by a three-point flexural test using the universal testing machine (UTM, INSTRON, NVLAP, USA). The rectangular bars were prepared with dimensions of $3 \mathrm{~mm} \times 4 \mathrm{~mm} \times 36 \mathrm{~mm}$, and the crosshead speed was set to $0.5 \mathrm{~mm} / \mathrm{min}$. The three-point flexural strength $\left(\sigma_{f}\right)$ was calculated according to the following formula : 


$$
\sigma_{f}=\frac{3 F L}{2 b d^{2}}
$$

where $F$ is the load, $L$ is the length of the span, $b$ is the width of the specimen, and $d$ is the specimen thickness. The flexural strength data was computed based on an average of ten measurements of the specimens.

\section{Result And Discussion}

\subsection{Formation of mullite-cordierite composites granules by spray drying process}

The sintering process is used to produce mullite-cordierite composites with high mechanical strengths, low TECs, and dense structures. In the sintering process, several variables, such as the particle size distribution and morphology of the powders, sintering temperature, and sintering aids, affect the properties of the sintered body. The particle size distribution of the powders greatly influences the reaction rate as well as the sintering behavior. For example, in coarse powders having a low initial density due to non-uniform size and high agglomeration, the particles are separated by a large distance, resulting in a low densification rate. Hence, it is necessary to control the particle size distribution of the starting powders.

The particle size distributions of the starting powders before and after attrition milling are shown in Fig. 2. As shown in Fig. 2(a), for the mullite powder, the peck of the particle size distribution curve (which has a unimodal distribution) moved toward the smaller particle size, and the $D_{50}$ value decreased from 3.96 to $1.75 \mu \mathrm{m}$ after attrition milling. As shown in Fig. 2(b), the particle size distribution of the cordierite powder shifted from a bimodal distribution to a unimodal distribution, and the $D_{50}$ value decreased from 4.23 to $3.23 \mu \mathrm{m}$ after attrition milling. The SEM images in Fig. 2 indicate that the initial powders with various particle sizes became homogeneous powders with uniform and small particle sizes following the milling process. It was expected that the starting powders with sizes over $10 \mu \mathrm{m}$ would be crushed during the milling process.

Figure 3 shows the microstructure of the granules formed by spray drying the mixed powders of mullite and cordierite before and after attrition milling. It shows the dependence of the particle size distribution of the mullite and cordierite powders on the formation of granules. Granules formed using the initial starting powders before attrition milling were found to have different morphologies (Fig. 3(a)). In contrast, the granules formed using starting powders with homogeneous size distribution obtained through the attrition milling process were found to be spherical (Fig. 3(b)). Moreover, the $D_{50}$ value of the unmilled mixed powders $(147.3 \mu \mathrm{m})$ was larger than that of the attrition milled mixed powders $(88.31 \mu \mathrm{m})$. The span defined as $\left(D_{90}-D_{10}\right) / D_{50}$, indicates the width of the particle size distribution. The unmilled mixed powders had a larger span. The span before the attrition milling was 1.22 and span after the attrition 
milling was 0.71 . These results show that the particle size and the size distribution of the initial powder affects the morphology of granular powders obtained by spray drying. In a previous work, it was shown that the granules obtained from finer initial powders and powders with a narrow size distribution formed smoother and denser structures, when compared to the large initial powders. Furthermore, the spherical granules of the powders have good flowability, which is an important factor in the fabrication of dense and mechanically strong ceramics [21]. Therefore, the spherical granules obtained by spray drying the fine powders after attrition milling are suitable for fabricating the mullite-cordierite composite pellets and substrates.

\subsection{Characterization of the sintered mullite-cordierite composite pellets produced by varying the cordierite content}

It is important to determine the optimal composition ratio and sintering temperature to improve the mechanical and physical properties of the sintered mullite-cordierite composite pellets before fabricating a large-area composite ceramic substrate. First, the effect of the composition ratio on the sintered mullitecordierite composite pellets was characterized. Figure 4 shows the SEM micrographs of the fractured surfaces of the mullite-cordierite composite pellets with various cordierite weight ratios $(0,10,30,50,70$, and $100 \mathrm{wt} \%$ ) sintered at $1300^{\circ} \mathrm{C}$. A porous structure was observed in the sample with $100 \mathrm{wt} \%$ cordierite, while the sample with $100 \mathrm{wt} \%$ mullite exhibited a more compact structure. For samples of pure cordierite and mullite, the density (cordierite $=2.55 \mathrm{~g} / \mathrm{cm}^{3}$ and mullite $=3.02 \mathrm{~g} / \mathrm{cm}^{3}$, respectively) was measured to be similar to the average theoretical density (cordierite $=2.53 \mathrm{~g} / \mathrm{cm}^{3}$ and mullite $=3.17 \mathrm{~g} / \mathrm{cm}^{3}$, respectively) [22], which is attributed to the structure of the samples, as shown in Fig. 4(a) and 4(f). As the mullite content in the composite pellets increased, the density noticeably increased as shown in Fig. 4(c)-(e), compared to Fig. 4(b). Thus, increasing the content of mullite not only accelerates densification during the sintering process, [23] but also increases the overall density of the samples as the density of mullite is higher than that of cordierite. Furthermore, a previous study reported that in batches with $>90$ $w t \%$ cordierite, the cracks formed by cristobalite transition from $\beta$ to a weakened the structure of the sample [22].

Figure 5 shows the effect of the cordierite content on the TEC and the flexural strength of the sintered composite pellets. Generally, to improve the thermal shock resistance, the ceramic substrate for probe cards requires a low TEC similar to Si. As shown in Fig. 5(a), the TEC of the samples decreased with increasing cordierite content. The sample containing $70 \mathrm{wt} \%$ cordierite was observed to have the lowest TEC $\left(2.88 \mathrm{ppm} /{ }^{\circ} \mathrm{C}\right)$ among all the samples (except the pure cordierite pellet) and exhibited excellent thermal shock resistance. However, compared to the TEC of Si $\left(3.2-3.9 \mathrm{ppm} /{ }^{\circ} \mathrm{C}\right)$ [24], it can be assumed that all composite pellets with 30-70 wt\% cordierite have good thermal stability. As shown in Fig. 5(b), the result is evidently observed that the flexural strength of the samples containing up to $30 \mathrm{wt} \%$ cordierite is higher than that of the samples containing over $50 \mathrm{wt} \%$ cordierite. This is because mullite has higher mechanical strength than cordierite. Thus, the flexural strength of samples with a large amount of mullite is higher. In addition, the figure shows the correlation between density and flexural 
strength. The flexural strength increases with increasing density as shown in Fig. 4 and Fig. 5(b). Therefore, it can be concluded that the composition ratio of $70 \mathrm{wt} \%$ mullite and $30 \mathrm{wt} \%$ cordierite is optimum for forming mullite-cordierite composites due to its low TEC and high flexural strength.

\subsection{Characterization of mullite-cordierite composite pellets sintered at different temperature}

Figure 6 shows the TEC and the flexural strength of sintered mullite-cordierite composite pellets of 70:30 wt\% for different sintering temperatures ranging from $1300^{\circ} \mathrm{C}$ to $1450^{\circ} \mathrm{C}$. As shown in Fig. $6(\mathrm{a})$, the TEC of the samples sintered at $1300^{\circ} \mathrm{C}$ and $1350^{\circ} \mathrm{C}$ was $3.45 \mathrm{ppm} /{ }^{\circ} \mathrm{C}$ and $3.42 \mathrm{ppm} /{ }^{\circ} \mathrm{C}$, respectively, which are similar to the TEC of Si. A significant increase in TEC can be observed for the samples sintered at $1400^{\circ} \mathrm{C}$ and $1450^{\circ} \mathrm{C}$. This is probably due to the thermal stress induced by the mismatch of the TEC between the glassy phase and the crystalline phases of mullite [25]. This result explains why the sample sintered at $1350^{\circ} \mathrm{C}$ is better able to withstand thermal stresses, compared to others samples prepared at different sintering temperatures. The physical and the mechanical properties, such as the density, porosity, flexural strength, and TEC, of the mullite-cordierite composites (70 wt\% mullite-30 wt\% cordierite) for different sintering temperatures are listed in Table 1 . The density at $1350^{\circ} \mathrm{C}$ is higher than that at $1300^{\circ} \mathrm{C}$. As the sintering temperature increases, some cordierite changes into glassy phase, which fills into the porosity of the mullite-cordierite composites [4, 22]. Over $1400^{\circ} \mathrm{C}$, however, all the cordierite melts and the sample consists of only the glassy phase, and the mullite content leads to decrease in density, leading to the large size of pores and the formation of macro cracks [25]. There is a high correlation between the density and the flexural strength, with higher density leading to higher flexural strength. Figure 6(b) can be explained using the density values listed in Table 1. The mullite-cordierite composite pellet sintered at $1350^{\circ} \mathrm{C}$ exhibits the most compact structure, which improves its mechanical properties. It can be confirmed that the flexural strength is the highest at $1350^{\circ} \mathrm{C}(264 \mathrm{MPa})$. The composite pellets sintered at other temperatures except $1350^{\circ} \mathrm{C}$, by contrast, show low flexural strength due to their relatively low density.

\section{Table 1}

Bulk density, porosity, flexural strength, and thermal expansion coefficient (TEC) of the mullite-cordierite composites at different sintering temperatures.

Codes content (wt $\%)$ Sintering temperature $\left({ }^{\circ} \mathrm{C}\right)$ Bulk density $\left(\mathrm{g} / \mathrm{cm}^{3}\right)$

Porosity (\%) Flexural strength (MPa) TEC (ppm/ $\left.{ }^{\circ} \mathrm{C}\right)$

\begin{tabular}{|c|c|c|c|c|c|c|}
\hline \multirow{4}{*}{ Mullite : Cordierite } & \multirow{4}{*}{$70: 30$} & 1300 & 3.02 & 0.20 & 226 & 3.45 \\
\hline & & 1350 & 3.07 & 0.19 & 264 & 3.42 \\
\hline & & 1400 & 3.01 & 0.21 & 224 & 3.85 \\
\hline & & 1450 & 2.94 & 0.23 & 196 & 4.08 \\
\hline
\end{tabular}

\subsection{The reliability and durability of the large-area mullite- cordierite composite substrate}


Based on the above results, a large-area mullite-cordierite composite substrate was fabricated by sintering at $1350^{\circ} \mathrm{C}$ using granules having a composition ratio of $70 \mathrm{wt} \%$ mullite- $30 \mathrm{wt} \%$ cordierite. The large-area ceramic composite substrate is $320 \mathrm{~mm}$ in diameter. The thickness of the substrate is approximately $5.7 \mu \mathrm{m}$, and the relative standard deviation of the thickness is $0.07 \%$, which means that it has a highly uniform thickness as shown in Fig. 7(a). To form the fine pitch of the probe card, 30000 micro-holes were processed in the large-area substrate through ultrasonic drilling. The size and position deviation of the holes were measured to investigate the shrink rate of the large-area substrate that occurred during the sintering process, as shown in Fig. 7(b) and 7(c). The SEM images in Fig. 7(b) show the cross sections of the ceramic substrate with the processed micro-holes. The measured average sizes of the top, middle and bottom section of the processed holes were $416.3 \mu \mathrm{m}, 400.1 \mu \mathrm{m}$ and $387.8 \mu \mathrm{m}$, respectively, having a deviation of $<5 \%$. Figure 7 (c) shows enlarged SEM images of the four sections marked \#1 to \#4 in Fig. 7(a). The distance between the holes was measured in four places in each of the SEM images, and the standard deviation of the distance was found to be $<3 \%$. These results reveal that the processed holes of the large-area ceramic substrate are formed evenly and that the shrinking of the substrate hardly occurred during the sintering process.

In order to evaluate the reliability and the durability of the large-area ceramic composite substrate, the substrate was cut into specimens with dimensions of $80 \mathrm{~mm} \times 80 \mathrm{~mm}$ and subjected to environmental tests, such as the HTS test, DH test, and TS test. Figure 8 shows the changes in the sheet resistance of the specimens during the environmental tests. In the HTS test, the specimens were placed in an oven at $200^{\circ} \mathrm{C}$ for more than $100 \mathrm{~h}$. There is no significant difference between the changes in the sheet resistance of the specimens before and after the HTS test. It is clear that the ceramic substrate is stable even when exposed to high temperatures for a long time. In the $\mathrm{DH}$ test, the specimens were exposed to a relative humidity of $85 \%$ at $85^{\circ} \mathrm{C}$. The rate of change in resistance was nearly constant. It can be seen that the absorption of moisture hardly occurred due to the high temperature and the high humidity. Compared to the other environmental tests, a larger change was observed in the sheet resistance of the specimen when it was subjected to TS test of over 100 cycles in a temperature range from $-40^{\circ} \mathrm{C}$ to $85^{\circ} \mathrm{C}$. The change in sheet resistance was caused by the impact of the thermal shock. However, the rate of change in the resistance was not large, which means that ceramic substrate was not significantly affected by sudden temperature changes. In Kiattisaksophon et al. [4], a mullite-cordierite composite of $30: 70 \mathrm{wt} \%$ was subjected to the TS test by heating the sample to $1100^{\circ} \mathrm{C}$ and cooling to room temperature. No damage was observed on the surface of the composite body until the 8th cycle, but the spot of micro-cracks was observed in the 9 th cycle. Compared to previous studies $[4,9,14,24,26]$, the TS test was performed in a harsher environment at low temperature, although the applied temperature range is slightly different. In all the environmental test results, the fabricated specimens exhibited a low resistivity change $<10 \%$, and no micro-cracks on the surface of the sample were observed even after 100 cycles. These results prove that the ceramic substrate has excellent reliability and durability.

The influence of the environmental tests on the flexural strength of the ceramic substrate is shown in Table 2. Specimens with dimensions of $3 \mathrm{~mm} \times 4 \mathrm{~mm} \times 36 \mathrm{~mm}$ were prepared for the measurement of flexural strength, and the result was computed as the average of ten measurements of the specimens. On 
comparing the flexural strength of the specimens before and after each environmental test, the flexural strength of all the specimens was observed to decrease slightly after the environmental tests. It can be assumed that the thermal stress can generate an impurity, which affects the physical properties [26]. In the research of Cheng et al. [27], it was reported that the flexural strength of the specimen with the best thermal property was about $90 \mathrm{MPa}$ and the loss rate of flexural strength was $13.12 \%$, after 30 thermal shock cycles. Compared to the composites reported in previous studies [27, 28], the fabricated large-area mullite-cordierite composite substrate has excellent mechanical strength. This is because it has a high flexural strength of $200 \mathrm{MPa}$ or more and the rate of change in the flexural strength is less than $10 \%$, after 100 cycles of all environmental tests.

\section{Table 2}

Variation of the flexural strength with the degradation time under high temperature storage test $\left(200^{\circ} \mathrm{C}\right)$, damp heat test $\left(85^{\circ} \mathrm{C} / 85 \%\right)$, and thermal shock test (between -40 and $85^{\circ} \mathrm{C}$ ).

\begin{tabular}{|c|c|c|c|c|c|c|}
\hline & \multicolumn{2}{|c|}{$\begin{array}{l}\text { High temperature storage test } \\
\qquad\left(200^{\circ} \mathrm{C}\right)\end{array}$} & \multicolumn{2}{|c|}{$\begin{array}{l}\text { Damp heat test } \\
\left(85^{\circ} \mathrm{C} / 85 \%\right)\end{array}$} & \multicolumn{2}{|c|}{$\begin{array}{l}\text { Thermal shock test } \\
\left(-40^{\circ} \mathrm{C} / 85^{\circ} \mathrm{C}\right)\end{array}$} \\
\hline & Before & After & Before & After & Before & After \\
\hline Flexural strength (MPa) & $229.28 \pm 6.2 \%$ & $223 \pm 7.5 \%$ & $224.34 \pm 9.7 \%$ & $216 \pm 8.5 \%$ & $227.40 \pm 7 \%$ & $218.10 \pm 10 \%$ \\
\hline
\end{tabular}

Consequently, the large-area substrates fabricated using spherical $70 \mathrm{wt} \%$ mullite-30 wt\% cordierite granules with homogeneous particle size distribution were not considerably affected after environmental tests to accelerate fatigue failure. These results prove the high reliability and durability of the fabricated composite.

\section{Conclusions}

The sintered mullite-cordierite composite pellets were produced from spherical composite granules, which were prepared by spray drying the fine mixed powders obtained from attrition milling. The composition ratio and the sintering temperature were varied to obtain the composite pellet with excellent physical and mechanical properties. In particular, the mullite-cordierite composite pellet containing $70 \mathrm{wt} \%$-mullite and $30 \mathrm{wt} \%$-cordierite sintered at $1350^{\circ} \mathrm{C}$ showed excellent performance. The fabricated composite has a bulk density of $3.07 \mathrm{~g} / \mathrm{cm}^{3}$, a porosity of $0.19 \%$, a TEC of $3.42 \mathrm{ppm} /{ }^{\circ} \mathrm{C}$, and flexural strength of $264 \mathrm{MPa}$. Although the composite pellet with $30 \mathrm{wt} \%$ cordierite sintered at $1300^{\circ} \mathrm{C}$ was a higher TEC than the composite pellet with $70 \mathrm{wt} \%$ cordierite, $70 \mathrm{wt} \%$ mullite-30 wt\% cordierite was chosen as the best composition ratio because its TEC is within the allowable range for the probe card substrate, and its flexural strength is higher than that of samples containing other amounts of cordierite. Based on this result, a large-area ceramic composite substrate with a diameter of $320 \mathrm{~mm}$ and a thickness of $5.7 \mu \mathrm{m}$ was successfully fabricated. Moreover, the rate of change in sheet resistance and the flexural strength was confirmed to be within $10 \%$ in the fabricated ceramic substrate after exposure to different environmental tests, such as HTS test, DH test, and TS test, indicating good reliability and durability. 
Thus, the mullite-cordierite composite can be considered as a suitable substrate material for the probe card.

\section{Declarations}

\section{Acknowledgments}

The research was supported by a Research Grant from Kwangwoon University in 2021 and Korea Institute for Advancement of Technology (KIAT) grant funded by the Korea Government (MOTIE) (P0012451, The Competency Development Program for Industry Specialist). In addition, this work was supported by the National Research Foundation of Korea funded by the Korean Government (MSIP; Ministry of Science, ICT and Future Planning) (Nos.20012914, 2018R1D1A1B07047515, and 2020R1F1A1073491).

\section{References}

1. Hsu WH, Chou MC, Tsai HY (2017) Design and fabrication of anisotropic conductive film for application of probe card. Journal of Mechanics 33:655-661

2. Jung HW, Kim YJ, Park JH (2020) Study on estimation method for maximum temperature of multilayered micro-probe by joule-heating. Int J Precis Eng Manuf 21:1955-1964

3. Choe SH, Tanaka S, Esashi M. A matched expansion MEMS probe card with low CTE LTCC substrate. IEEE International Test Conference 2007, 1-6

4. Kiattisaksophon P, Thiansem S (2008) The preparation of cordierite-mullite composite for thermal shock resistance material. Chiang Mai J Sci 35:6-10

5. Reda AE, Abd-El-Raoof F, Ahmed SE et al. Sintering and dielectric behavior for doped cordierite by xCuO within $\mathrm{MgO}(1-\mathrm{x})-\mathrm{Al}_{2} \mathrm{O}_{3}-\mathrm{SiO}_{2}$ ceramics. Materials Chemistry and Physics 2020, 243: 122616

6. de Brito IP, de Almeida EP, de Araújo Neves G et al (2021) Development of cordierite/mullite composites using industrial wastes. Int J Appl Ceram Technol 18:253-261

7. Goren R, Gocmez H, Ozgur C (2006) Synthesis of cordierite powder from talc, diatomite and alumina. Ceram Int 32:407-409

8. Wu J, Hu C, Xu X et al (2016) Preparation and thermal shock resistance of cordierite-spodumene composite ceramics for solar heat transmission pipeline. Ceram Int 42:13547-13554

9. Albhilil AA, Palou M, Kozánková J et al (2015) Thermal and microstructure stability of cordieritemullite ceramics prepared from natural raw materials-part II. Arab J Sci Eng 40:151-161

10. Camerucci MA, Urretavizcaya G, Castro MS et al (2001) Electrical properties and thermal expansion of cordierite and cordierite-mullite materials. J Eur Ceram Soc 21:2917-2923

11. Banjuraizah J, Mohamad H, Ahmad ZA (2011) Densification and crystallization of nonstoichiometric cordierite glass with excess MgO synthesized from kaolin and talc. J Am Ceram Soc 94:687-694

12. Chen GH (2008) Sintering, crystallization, and properties of $\mathrm{CaO}$ doped cordierite-based glassceramics. J Alloy Compd 455:298-302 
13. Chen GH (2007) Effect of $\mathrm{ZnO}$ addition on properties of cordierite-based glass-ceramics. J Mater Sci: Mater Electron 18:1253-1257

14. Albhilil AA, Palou M, Kozánková J (2016) Characterization of cordierite-mullite ceramics prepared from natural raw materials. Acta Chimica Slovaca 6:1-7

15. Yan W, Chen J, Li N et al (2015) Lightweight cordierite-mullite refractories with low coefficients of thermal conductivity and high mechanical properties. Bull Mater Sci 38:409-415

16. Hou Z, Cui B, Liu L et al (2016) Effect of the different additives on the fabrication of porous kaolinbased mullite ceramics. Ceram Int 42:17254-17258

17. Kool A, Thakur P, Bagchi B et al (2015) Mechanical, dielectric and photoluminescence properties of alumina-mullite composite derived from natural ganges clay. Appl Clay Sci 114:349-358

18. Andrade RM, Araújo AJ, Alves HP et al (2019) On the physico-mechanical, electrical and dielectric properties of mullite-glass composites. Ceram Int 45:18509-18517

19. Subramanian MA, Corbin DR, Chowdhry U (1993) Better ceramic substrates through zeolites. Bull Mater Sci 16:665-678

20. ASTM C20-00 (2015) Standard test methods for apparent porosity, water absorption, apparent specific gravity, and bulk density of burned refractory brick and shapes by boiling water. ASTM International, West Conshohocken

21. Stunda-Zujeva A, Irbe Z, Berzina-Cimdina L (2017) Controlling the morphology of ceramic and composite powders obtained via spray drying-a review. Ceram Int 43:11543-11551

22. Khattab RM, El-Rafei AM, Zawrah MF (2012) In situ formation of sintered cordierite-mullite nanomicro composites by utilizing of waste silica fume. Mater Res Bull 47:2662-2667

23. Ozel E, Kurama S (2010) Effect of the processing on the production of cordierite-mullite composite. Ceram Int 36:1033-1039

24. Lim JH, Kim SY, Yeo DH et al (2017) Effect of $\mathrm{Cr}_{2} \mathrm{O}_{3}-\mathrm{MgO}-\mathrm{Y}_{2} \mathrm{O}_{3}$ addition on mechanical properties of mullite ceramics. Journal of the Korean Institute of Electrical Electronic Material Engineers 30:762767

25. Zhang L, Olhero S, Ferreira JM (2016) Thermo-mechanical and high-temperature dielectric properties of cordierite-mullite-alumina ceramics. Ceram Int 42:16897-16905

26. Wu J, Lu C, Xu X et al (2019) Preparation of cordierite-mullite ceramics for solar thermal storage. Journal of Wuhan University of Technology-Mater Sci Ed 34:1062-1070

27. Cheng $\mathrm{H}, \mathrm{Ye} F$, Chang $\mathrm{J}$ et al (2019) In situ synthesis and thermal shock resistance of a cordieritemullite composite for solar thermal storage. Int J Appl Ceram Technol 16:772-780

28. Sittiakkaranon S. Thermal shock resistance of mullite-cordierite ceramics from kaolin, talc and alumina raw materials. Materials Today: Proceedings 2019, 17: 1864-1871

\section{Figures}




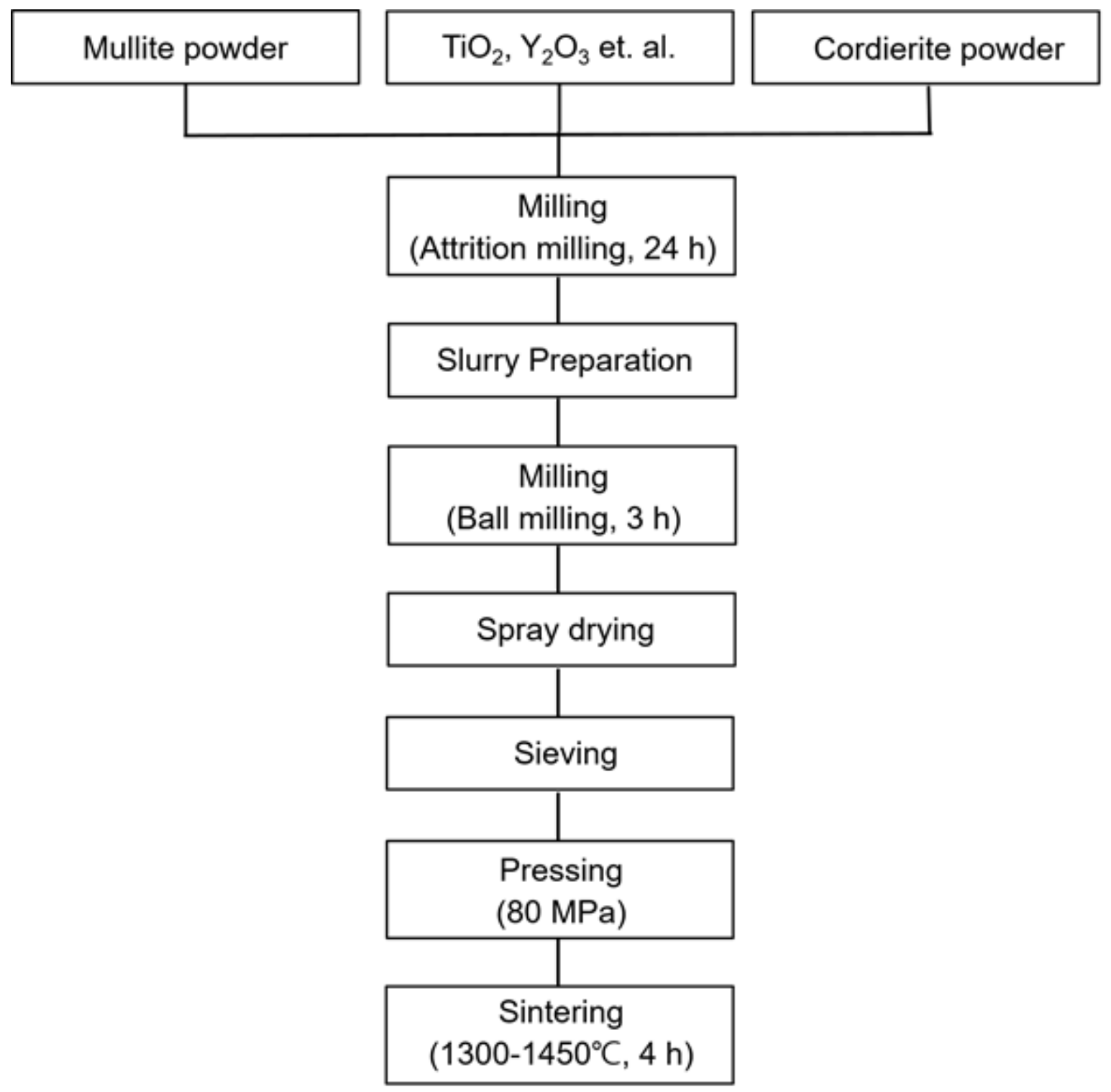

Figure 1

Flow diagram of the experiment procedure.
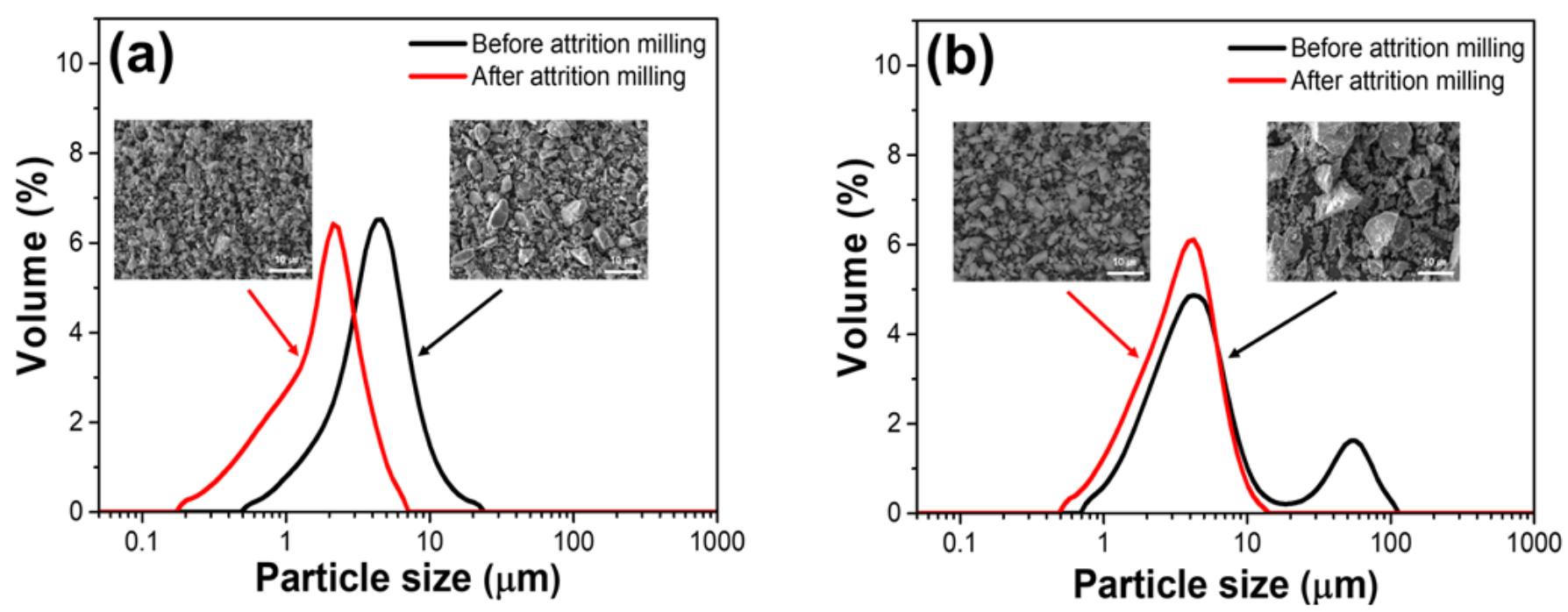


\section{Figure 2}

Particle size distributions of the starting powders: (a) mullite and (b) cordierite. The inset images show the SEM micrographs before and after attrition milling of the starting powders (mullite, cordierite).
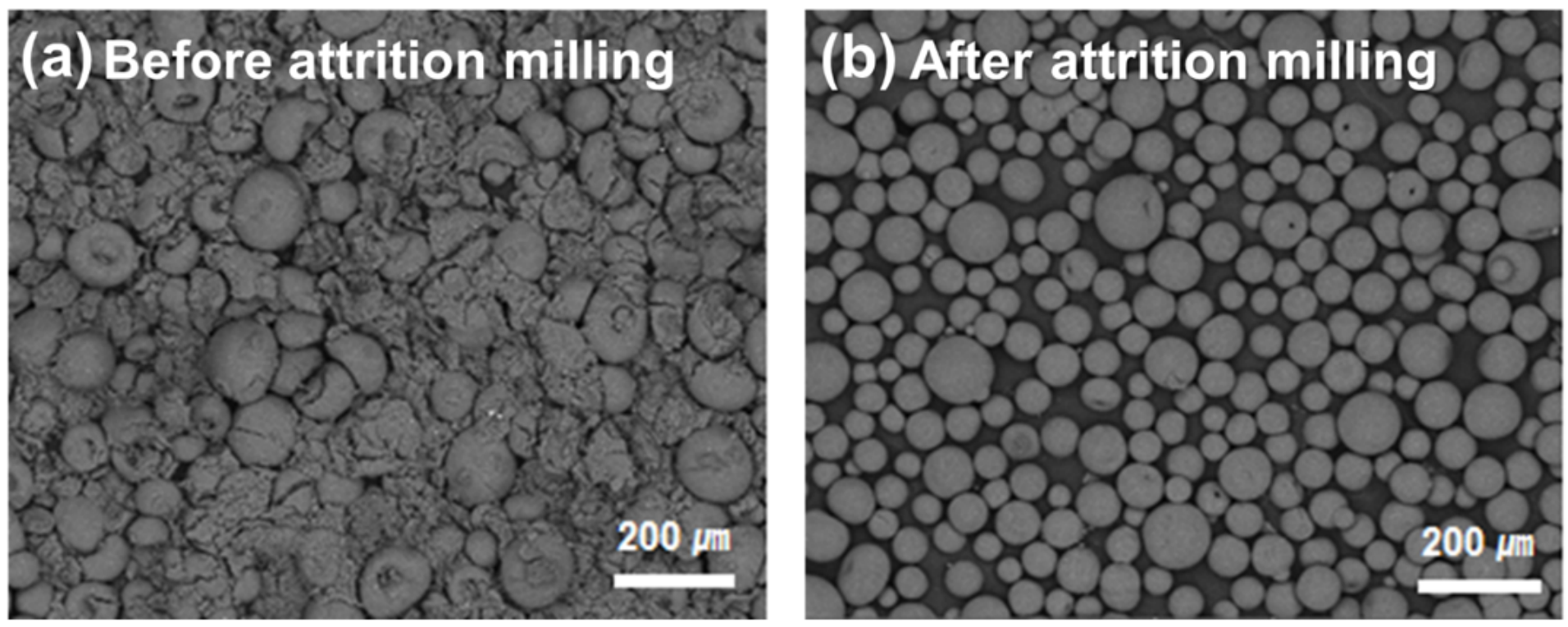

\section{Figure 3}

SEM images of the mullite-cordierite composite granules: (a) before and (b) after attrition milling.
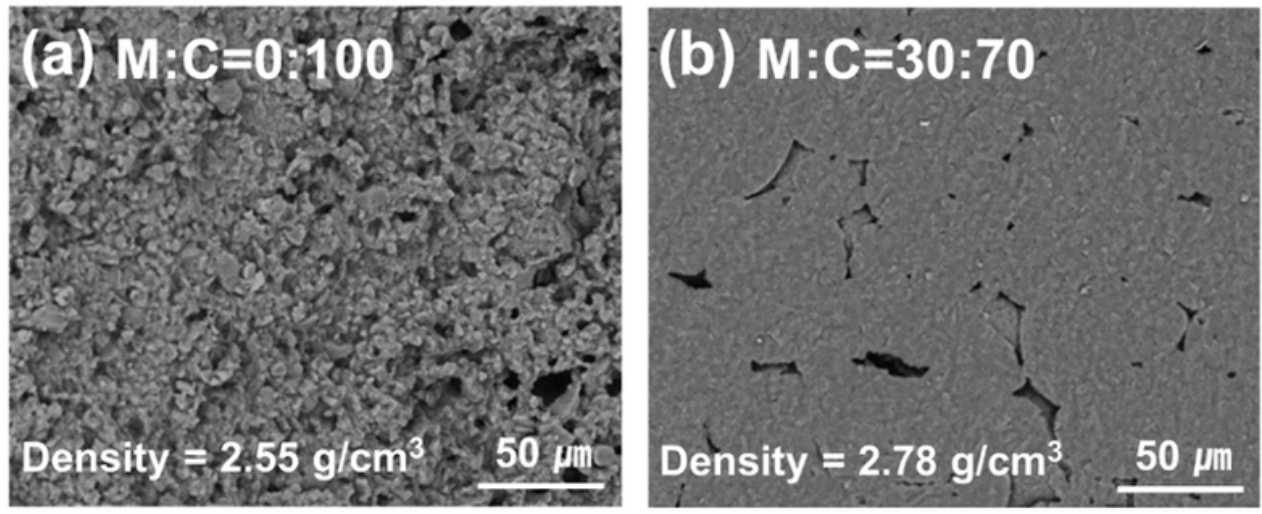

(c) $M: C=50: 50$

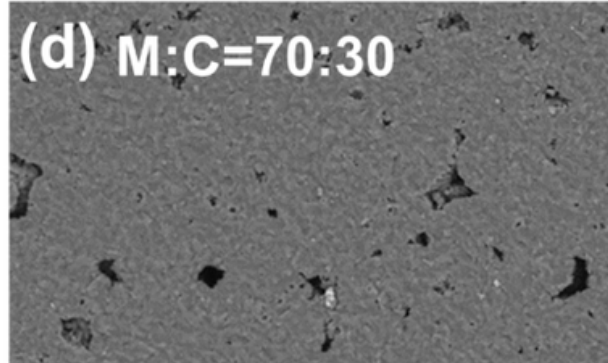

Density $=2.98 \mathrm{~g} / \mathrm{cm}^{3} \quad 50 . \mu \mathrm{m}$
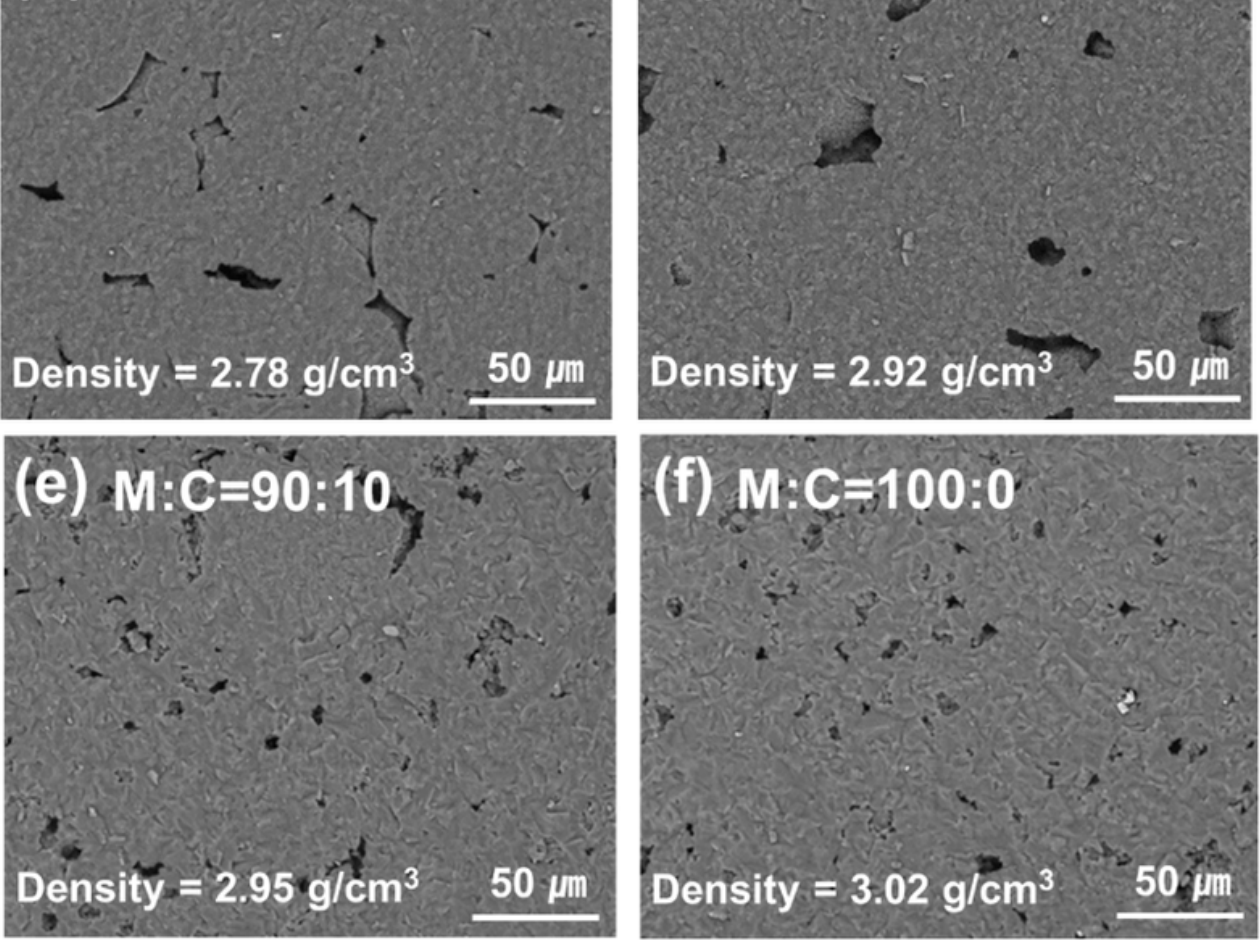

(f) $M: C=100: 0$

Density $=3.02 \mathrm{~g}^{3} \mathrm{~cm}^{3} \quad 50 \mathrm{jm}$

\section{Figure 4}


SEM images of the mullite-cordierite composite sintered at $1300^{\circ} \mathrm{C}$ : (a) $M: C=0: 100$, (b) $M: C=30: 70$, (c) $M: C=50: 50$, (d) $M: C=70: 30$, (e) $M: C=90: 10$, and (f) $M: C=100: 0$.
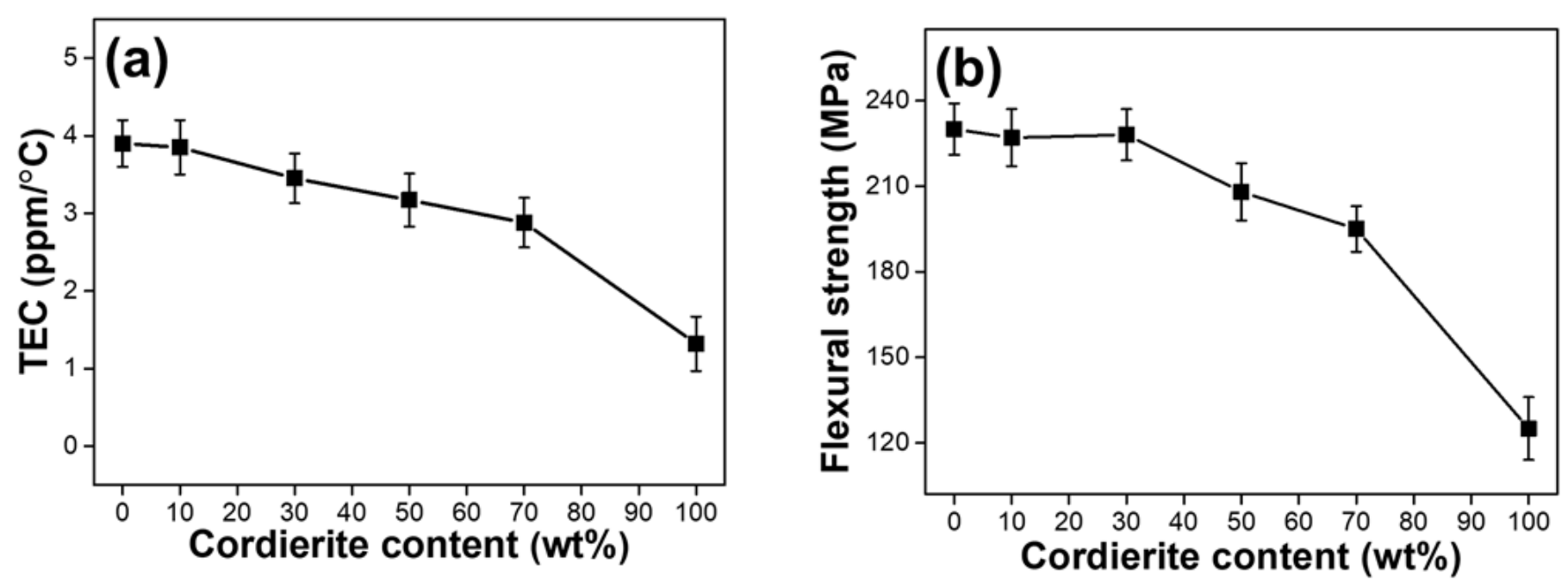

Figure 5

Variation in the thermal expansion coefficient (TEC) and the flexural strength of mullite-cordierite composites with the cordierite content.
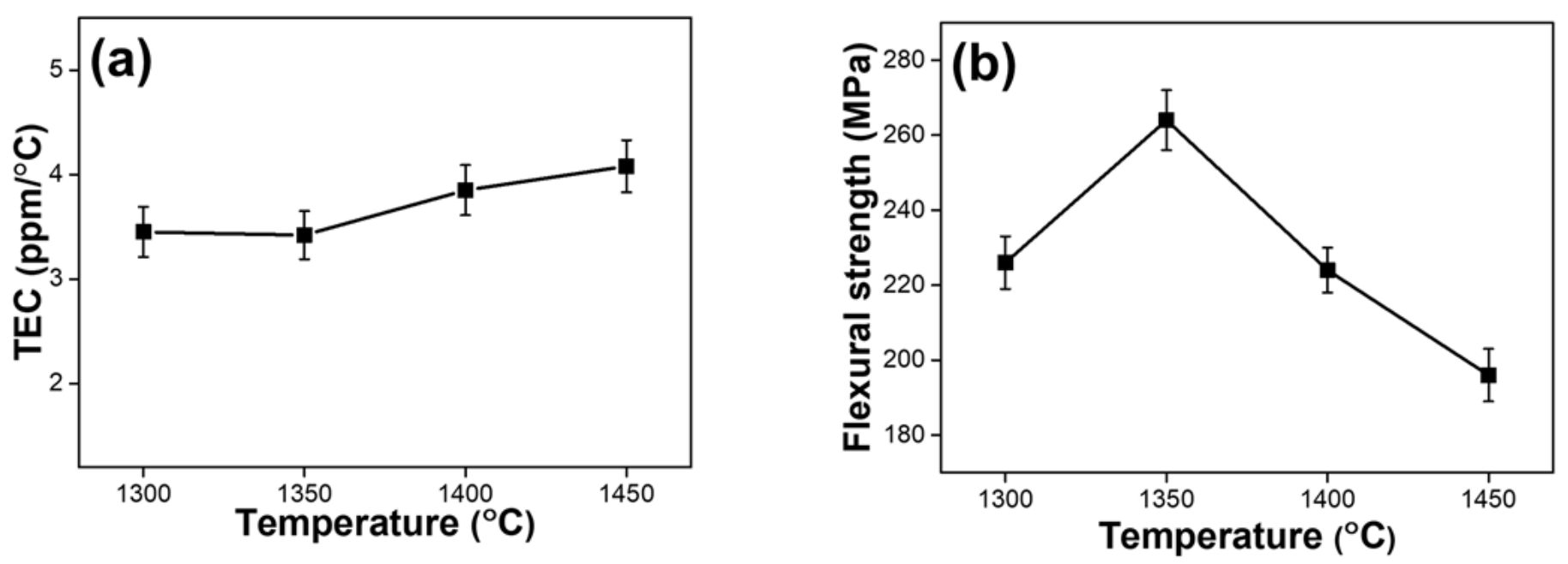

Figure 6

Variation in the thermal expansion coefficient (TEC) and the flexural strength of mullite-cordierite composites for different sintering temperature. 

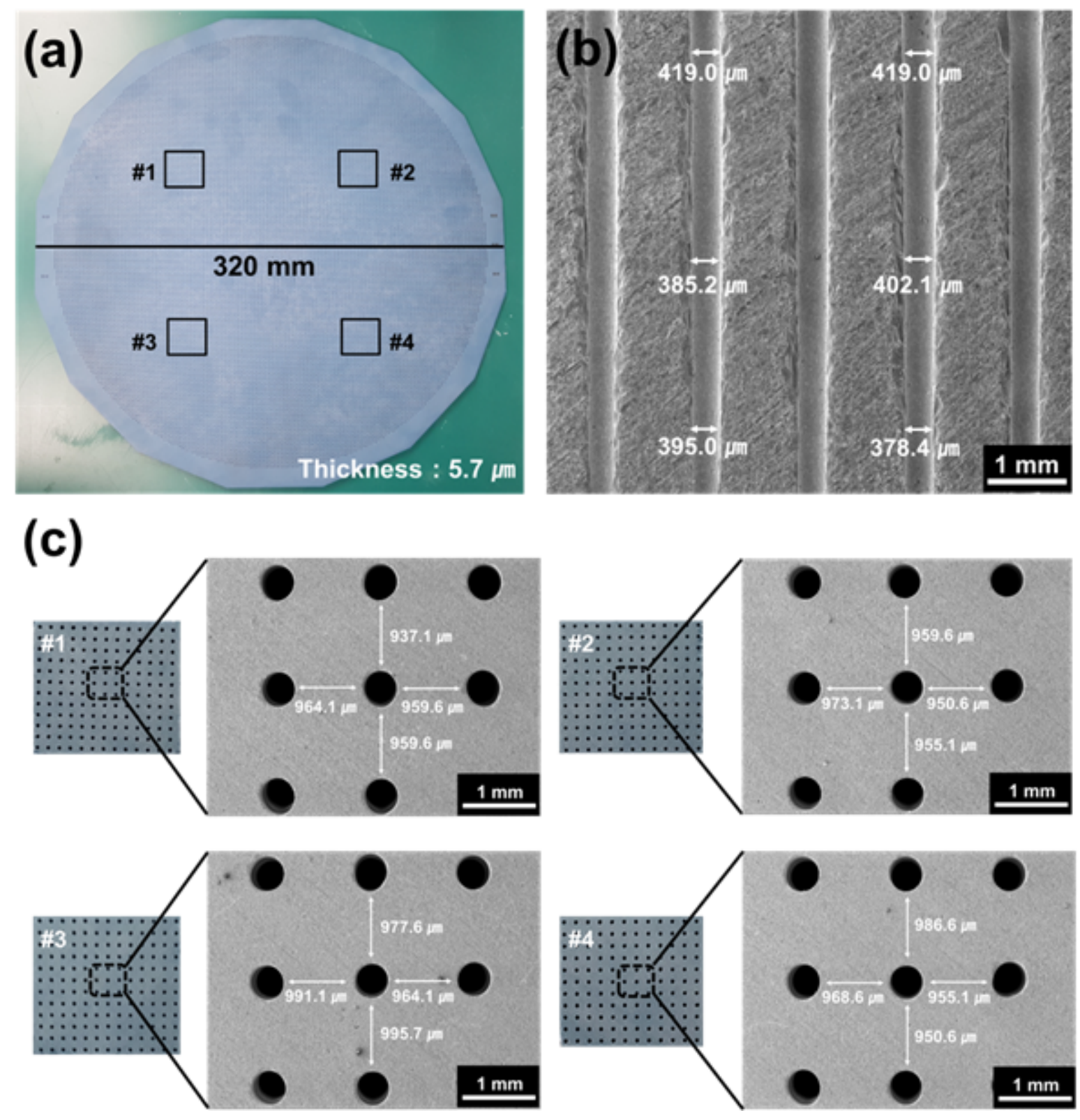

Figure 7

The ceramic substrate fabricated by using mullite-cordierite composite containing $70 \mathrm{wt} \%$ mullite-30 wt\% cordierite sintered at $1350^{\circ} \mathrm{C}$. 


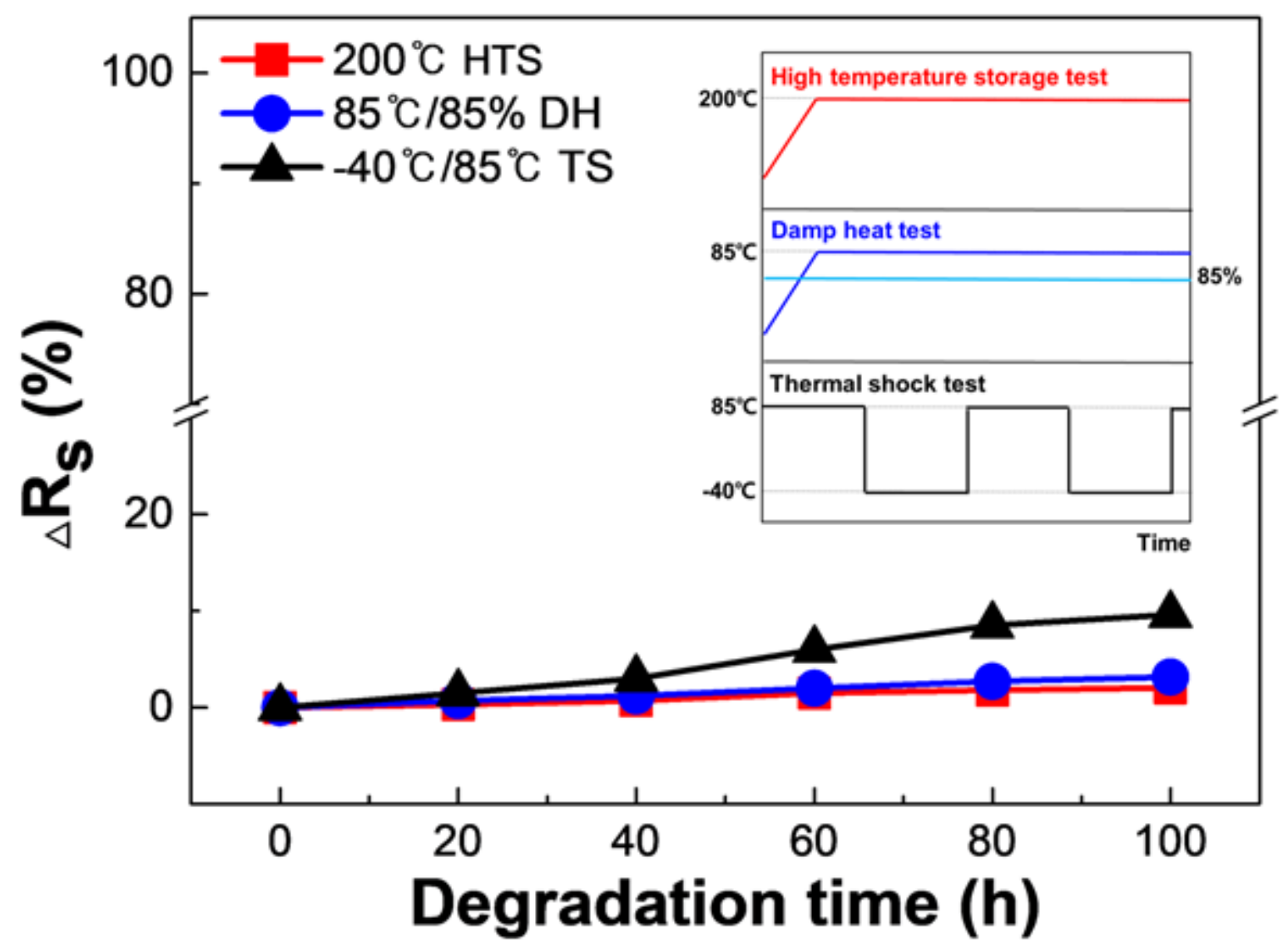

Figure 8

Variation in the sheet resistance of ceramic substrate under high temperature storage test $\left(200^{\circ} \mathrm{C}\right)$, damp heat test $\left(85^{\circ} \mathrm{C} / 85 \%\right)$, and thermal shock test (between -40 and $\left.85^{\circ} \mathrm{C}\right)$. The inset graph shows a schematic of the harsh environmental tests to which the ceramic substrate is subjected. 